\title{
ONLINE PERSONA RESEARCH: AN INSTAGRAM CASE STUDY
}

\author{
Kim Barbour, Katja Lee \& Christopher Moore
}

\section{INTRODUCTION}

In the last issue's editorial, "Five dimensions of online persona" (Moore, Barbour \& Lee 2017), we turned our attention to the proliferation of public identities through online platforms, and traced key nodes of research that inform how we think about and theorise online personas. We also proposed and outlined five primary dimensions to the online persona that we characterised as public, mediatised, performative, collective, and having intentional value. The scope of that work was deliberately broad and far-reaching - we envisioned that piece as neither tool nor template but, we hoped, a conceptual starting point for further thinking and research.

In this editorial, we seek to continue that work by putting these theoretical foundations and concepts into practice through a study of the persona work of Instagram. This work constitutes, in many cases, significant labour: decisions are made and remade around sharing different types of images, along with the use of hashtags, framing, timing, filters, captions, or tags. Abidin (2016b, p. 90) describes this as "visibility labour", which is "the work individuals do when they self-posture and curate their self-presentations so as to be noticeable and positively prominent" to their audiences or micro-publics, and notes that the labour itself becomes invisible in the persona creation process. This distributed visibility labour forms the basis of persona work, where users and their micro-publics, in conjunction with the platform and the algorithms that drive it, are continually iterating on the persona that is produced.

With over 800 million users active on a monthly basis (and 500 million on a daily basis), Instagram is a tremendously popular platform for creating and sharing photographs and videos (Instagram 2017). Through both the content uploaded and the activities of sharing, the platforms' users are heavily involved in persona work. Although not always framed in terms of persona, scholars have been intrigued by the identity practices of Instagram users from the visual media offered by public figures and celebrities to how Instagram content and activities respond to, influence, and depict physical, emotional, and psychological health (Brown \& Tiggemann 2016; Djafarova \& Rushworth 2017; Duguay 2017; Highfield \& Leaver 2016; Leaver \& Highfield 2018; Markham 2015; Moon et al. 2016; Moreno et al. 2016; Olszanowski 2014; Pittman \& Reich 2016; Zappavigna 2016). However, the vast majority of users are not public figures and, indeed, much content and activity on Instagram is not very glamorous and more mundane. In our case study, we pointedly take up the everyday and the (potentially) banal, by tracing a singular hashtag, \#watchingtv, as an opportunity to not only understand how Instagram users are performing the watching of television, but to think through and experiment with different methodological practices. Online persona research is, we contend, not easy. When online persona performances are continuously changing, updating, and revising, our scope of study is both rich and potentially overwhelming. We must grapple with issues of the volume, boundaries, and interconnectedness of our texts, as well as sample size, reading strategies, the mutability and temporal nature of some archives, the legal frameworks defined by the platform's Terms of Use and Privacy Policy, and a broad range of other considerations. Core to all of this must remain Highfield and Leaver's (2016) emphasis that scholars must consider the 
role they play in potentially surfacing and amplifying content that, despite technically being publicly accessible, may have instead been intended and experienced as a more private engagement with photo sharing.

\section{The Dimensions of Instagram Persona Work}

Although celebrities and other public figures can legitimately lay claim to having more followers, the practical reality of Instagram is that the vast majority of the 800 million plus monthly users are everyday folk capturing and sharing visual representations of both the exciting and everyday aspects of their lives. Therefore, Instagram followers are intentionally moving into public, even when on a relatively small scale, or with a private account, and, as Lee (2016, p. 220) has argued elsewhere, "the individual [...] who moved or authorises the movement of the private into the public has entered the realm of image management and public relations". Instagram, as we know, is not in this sense particular. Such movement into and through online publics is the raison d'être of social media platforms, and Instagram's particular contribution is popularising the role of visual media in that project.

Like other platforms, Instagram also has a "particularly wide-ranging spectrum of publicness" (Moore et al. 2017) wherein users might operate within contained and regulated publics but have opportunities to broaden that scope and enter (and entertain) a global public audience. The role and function of the hashtag has been much discussed in this respect (Alam et al. 2017; Highfield \& Leaver 2015, 2016; Leaver \& Highfield 2018), yet of particular interest to us is the persona work that is done when hashtags move Instagram users beyond their micropublics (Marshall 2014) to broader publics, and signal a desire to not only contribute to and participate in particular conversations, but mark and legitimise specific archives and taxonomies. By inviting viewers to consider the relation between the image and the tag, hashtags also provide opportunities for performances of wittiness and cleverness to sarcasm, politics, and even dullness: \#dog, when accompanied by a picture of a dog, indicates a movement from the individual's relationship to the animal, towards a much larger public of dog owner's sharing their images via the platform. \#dog is broad enough to be both potentially banal and very flexible, inclusive of a whole range of content not related to animals, yet it specifically and intentionally seeks out an enormous public in ways that a specific breed, such as \#havanese, does not (assuming \#havanese is not also accompanied by \#dog). This use of many hashtags also does persona work and signals a desire to enhance the richness of one's Instagram experience and broaden their networks. While to some the extensive use of hashtags might be read as unseemly or over-eager, the proliferation of tags signals a readiness to participate and be represented across multiple conversations and interests.

The public nature, movement, and momentum of the hashtag, like the Instagram user's activities in general, are inseparable from a consideration of another key dimension of online persona-the connectivity that results in collectives (Moore et al. 2017, p. 5). As a platform, Instagram enables users to reach across multiple platforms by publishing their images simultaneously on Facebook and Tumblr, with an image link posted to Twitter. This interconnectivity and interoperability of Instagram broadens not just the reach of the user's content and activity, but the richness and complexity of the persona work that is done within and across networks and collectives. This feature of Instagram is built upon increasing levels of comfort, skill, and degrees of naturalisation of public mediatisation, and, in particular, a visual production and performance of that mediatisation. With the popularisation of the built-in camera feature on mobile phones for capturing images (still and moving), and internet connectivity enabling rapid and effective sharing of these images, we have become particularly skilled and adept producers of visual images in the last decade for both personal and 
professional purposes. For many of us, these skills have come through play and experimentation on personal devices, but for younger generations this is often augmented by formal training as well. For example, in a first-year course in Communication and Media Studies at the University of Western Australia, students develop image production and manipulation skills, and must produce a series of Image Tasks and a final Remediation Portfolio project. Students in the media program at the University of Adelaide are assessed on their abilities to produce and maintain presences in a number of online platforms. At the University of Wollongong, students in the Bachelor of Communication and Media are required to curate an online presence across multiple platforms, responding to weekly tasks which require them to create visual media including Tweeted memes and gifs, Snapchat and Instagram posts, and online video.

\section{A CASE STUDY OF \#WATCHINGTV}

The impetus behind the \#watchingtv pilot project was to investigate the photography of banal activity as a way of understanding how people perform an element of everyday media consumption. Through an analysis of the photographs posted to Instagram, along with a hashtag analysis associated with the images, this particular case study focuses on how people visualise the ways they perform the activity of television watching from their homes. This previously private undertaking - the activity of watching television in domestic spaces-is being surfaced by the prevalence of the public sharing of personal photography, and thus now contributes to the persona of the individual who produces and shares the images, or at least the persona presented through that account. As people turn to social media as a second screen to augment their engagement with television, building on earlier online communities and discussions, they are reaching out not just through their commentary on the shows they are watching (Baym 2000; Barbour 2016) but also through the presentation of their watching environment. This is a shift in our understanding of what constitutes the private realm of the home, as well as our understanding of the privacy of our leisure time, and the context in which this change is happening requires investigation. This study was also envisioned as an opportunity to experiment with methodologies of social media and persona research. While the data collection activities developed mechanisms for creating a meaningful but finite dataset for analysis, a thematic approach to engaging with these Instagram activities models a study of persona that is not built on unpacking individual or group identities, but instead on patterns of performances.

To produce this dataset, Barbour used the browser-based service Websta.me to search for posts tagged with \#watchingtv. (In an effort to maintain the in-the-moment nature of the postings, the active tense \#watchingtv tag was selected for study; at the time of writing, the hashtag had over 402,500 public posts (Websta 2017) making it the most popular tag of its type). Twenty posts were captured each day during the data collection period by using a screen shot, and then each image was coded. The research methodology and method of data collection were developed in response to the Instagrammatics approach outlined by Tim Highfield and Tama Leaver $(2015,2016)$. Although the data were collected manually through screenshots and a third-party application (Websta), rather than querying the Instagram API, the methodological design took into consideration Highfield and Leaver's (2015) key concern around conducting Instagram research: that the data is dynamic, in that each comment adds to the original post, rather than becoming a data point on its own. By manually accessing posts tagged \#watchingtv, the dataset avoided the inclusion of posts where the hashtag was mentioned in the comments (potentially repositioning the original post). However, given a common practice of a user listing out a range of descriptive hashtags in a comment under the original post, which may be a strategic choice in order to garner more likes and attention for the post (Abidin 2016b), this may have meant some images were excluded which may have been fruitful inclusions. Once 
coding and analysis was complete, the screenshots were deleted. In order to identify any differences in the types of images associated with the hashtag across the day and week, the most recently posted images were collected at $10 \mathrm{am}$ for the first seven days, at $12 \mathrm{pm}$ for the second seven days, and at $8 \mathrm{pm}$ for the final three days (Australian Central Daylight Time). Initially designed as a 28-day data collection period, it was determined that, for the purposes of this pilot study, data saturation was reached after seventeen days. This resulted in a data set of 340 posts. Case-by-case decisions regarding the age of the user were made during data collection, as ethics approval for the study excluded participants under eighteen years of age. These determinations were made using visual clues (school bags, teen décor), and textual clues (references to school, parents), as well as the users biographical statement. If there was doubt as to whether the user (in this case understood as the account holder) was eighteen or older, their post was excluded from the data.

The images were coded in a spreadsheet. This coding included the user handle (collected to allow for identification of repeat users), whether the image was a still photograph or a video, how many images were included (as in the case of collated images), and the visual elements of the image: number of adults and children, types of animals, inclusion of food, whether the television was in the frame. This coding schema was based on the first week's images, and was used consistently from that point forward. The captions and associated hashtags were also collected, as well as a short description of each image. The description was necessary to both provide a memory prompt as to what the image looked like, and to allow for analysis of the types of images, rather than purely noting the contents. As noted by Highfield and Leaver (2016, p. 48), "[t]he visual adds levels of trickiness to such analyses: first in accessing the images, videos, or other linked and embedded files, and then in studying them, which requires more individual intervention and interpretation than samples of 140characters". Some common notes made in the coding description related to framing or colour choices, that the image was poorly lit, or that the subjects were "watching intently" something outside of the frame; this was usually presumed to be the television referenced in the \#watchingtv tag. The frequency of these types of notations is key to understanding the types of images that were included in this data set-they were largely snapshots (poorly lit or framed) and the television was often implied by the gaze of the human or animal subject rather than included in the image itself.

Of the 340 posts that made up the final data set in this study, sixty-two captions included a reference to the show or film they were watching, with fifty-two distinct shows named. The captions alone were often difficult to decode and thus while it is possible this number is higher, this data set would still show fewer than twenty per cent of the posts referencing specific shows. ${ }^{i}$ Although a little under a fifth of the posts named what was being watched, using a hashtag connected to a media provider such as Netflix was significantly rarer. There were nine providers named in the data set, with Netflix referenced four times, and the BBC referenced twice. In total, only thirteen of the 340 posts in the data set named the provider or channel being watched.ii What these findings suggest is that with \#watchingtv, it is the broad reach of the (banal) activity and not the specific content, program, or even broadcaster that is the focal point (or one of the focal points) of the post. This is affirmed through visual analysis of the images which reveal that \#watchingtv is less about television and more about the conditions and contexts of watching; these not only give the activity new or altered significance but become a rich site of persona work.

Manovich (2016) describes three categories of image aesthetic as visible on Instagram: the casual, equivalent to a personal or family snapshot; the professional, which mirrors commercial photography in terms of following the rules of photography as laid down in the 
20th Century; and the designed, which uses flat layouts, shallow depth of field, and mirrors the style of contemporary graphic design. These categories correlate loosely with earlier distinctions in film photography between personal, amateur, and professional photography (Hand 2012, p. 7). The first is represented by the home snapshot, the second by images that show more care or technical skill in their production, but run the risk of being seen as pretentious (Rose 2010), and the third are those created for commercial purposes. Manovich's casual aesthetic would match to the personal domestic photography of the past, although encompasses a much more banal range of subjects. The designed aesthetic, meanwhile, is similar in intent and production to the idea of amateur photography while being quite different in terms of the qualities of the photographs themselves, given amateur photography utilises the traditions of structure, perspective, and deep depth of field that is rejected by the designed aesthetic. Finally, although there is an aesthetic relationship between the professional photography of each typology, Manovich's categorisation is of images produced without an outright commercial imperative (that is, the photographers do not make a living from their work).

All three of these photographic aesthetics can be seen on Instagram, but the first- the casual-characterises the vast majority of \#watchingtv images captured for this project. Rather than being intended to be beautiful or attention grabbing through their display of skill, these casual snapshots instead work as records of a moment in time and are shared in that moment for whomever might be watching. The casual domestic photograph, a style reflected in the bulk of the images in the \#watchingtv dataset, can be understood as the photographic answer to the question, 'What are you doing right now?' that prompted early Facebook users. These images are, in many ways, reminiscent of the genre of private and personal photography utilised for the purposes of the family photo album where photographic images record and stand in for memories (Hand 2012; Sontag 1979). Through these generic images, we understand who and what a family is; as Slater (1995, p. 130) comments, "it is through the family at leisure, at play, at busy rest, in a time of extraordinary ordinariness, that we have come to represent the family to its members and its publics". The banality of the images, of course, belies the complexity of family life. The carefully collated family albums speak to Barthes' (1981, p. 98) assertion that we "want to utter interiority without yielding intimacy". The albums testify to the domestic life we want to remember-holidays and celebrations and successes-rather than the everyday living that fits in between the photograph-worthy special events.

Unlike the family photography that appears in albums, these images may not show the same "very selective visions of [...] family life" (Rose 2010, p. 13), but rather are much more inclusive of the boring, the banal, the messy, and the momentary than a traditional family album. However, being largely composed of snapshots, and attracting minimal comments and favourites from other users, the posts in this dataset can be understood as personal communication, despite being shared publicly. In order to minimise any possible risk to the Instagram users who posted to \#watchingtv, it is necessary to "consider whether the act of researching surfaces material that would otherwise had little attention and whether amplifying that material through research and research reporting has the potential to do any harm" (Highfield \& Leaver 2016, p. 57). In reporting the results of the research below, we have opted to discuss aggregate findings rather than specific images. Equally, it is important to note that the users posting to \#watchingtv were not "seeking to be part of an imagined community" as had initially been anticipated, but rather the tag was used descriptively, "explaining to that user's existing audience the context and content of the media shared" (Leaver \& Highfield 2016, p. 5). The images stand in for personal contact, function as memoranda of the everyday lives of the photographers, and record the banalities of people's engagement with both the production and consumption of media. Yet it is in the contexts of that consumption and within the framework of 
those banalities that we detect both persona performances and the labour of making that visible. In connecting the consumption of television programming with the production of photographs in this data set, there emerged six key motifs within the photographs. These themes are labelled "Feet Up", "Snacks", “Pets", "Kids", "Date Night", and "Daddy Time".

\section{Feet Up}

The first motif identified running through the data set is a point of view shot with lower legs and feet in shot, which sometimes (if the photographer was horizontal enough) included stomach and groin as well. Feet were raised on coffee tables, chaise lounges, ottomans, sofas, cushions, and beds, sometimes covered with blankets or throws, usually alone but occasionally in pairs or threes, or with pets included. A distinctive feature was the television in the distance, usually too saturated or badly lit to allow the viewer of the photograph to identify what show was being watched. Perhaps not surprisingly, "Feet Up" images in various forms were incredibly prevalent, constituting ten per cent of all images in the data set. This image corresponds well with the idea of television viewing as a leisure activity, allowing people to relax in the privacy of their homes. In line with Zappavigna (2016, p. 9), we can understand the inclusion of the lower body as an invitation "to share in the experience represented" in real time, inferring the presence of the photographer through the angle, framing, and visibility of what is presumed to be the photographer's body. "Feet Up" images seem to visualise the sentiment "wish you were here" or, perhaps, "you could be here", but the subtext remains that you are not. The images are a performance of leisure that simultaneously includes and excludes the viewer, and that, in its angle and composition, seeks to render invisible the mediatisation of the moment while the sentiment ultimately recalls the presence of that mediated frame.

\section{Snacks}

Aligned with the role of television as a leisure activity that encourages relaxation is the second theme, which reflects the popularity of food imagery in social media. As reflected by the title of the theme, the photographs usually depicted junk food or treat food, but images of people's main meals were also included. This shot, despite the use of the \#watchingtv tag, often did not include the television in the frame, but rather was focused only on the food. In contrast to a lot of the food photography seen on Instagram, the \#watchingtv tag appeared not to attract food stylists or fans of "flat lays", whose images would usually feature "prevalent use of shallow depth of field and light-flooded settings" (Dejmanee 2016, p. 442). By contrast, these snapshots of snacks were in line with the domestic/personal photography. The images of snacks or other food were most often collections of food items dumped on a blanket, couch, or coffee table, and occasionally were taken after eating, showing empty bowls or packaging. ${ }^{. i i}$ It is a motif that suggests not just the privilege of leisure but also desirable forms of consumption: adding a \#watchingtv hashtag to food imagery is a cumulative "piling on" of pleasure.

\section{Pets}

Of the 340 posts, 128 contained petsiv; of those, 112 were focused solely on the animal to the exclusion of the possible people in the room. This popular motif often sought to demonstrate the poster's sense of humour. These images were generally accompanied by captions poking fun at either the animal or the photographers themselves. Where pets are overly ambitious in their attention to the screen-for example, housecats watching shark week, or lapdogs watching sheep herding - the captions would often reflect on the absurdity. In addition to posts of pets actively watching television, there was also a secondary theme featuring animals that had fallen asleep with their paws or heads on the remote control. 


\section{Kids}

Despite the continued debate as to the advisability of sharing photographs of children online, often presented as dangerous or exploitative in the popular media (Appleton 2017; Blatchford 2016; Haelle 2016; Kelion 2017; Orlando 2016), images of young children-babies, toddlers, and primary schoolers-were prevalent in the data set. Of the 340 posts, forty-one contained children in the image, both as the focus of the photograph, and as incidental to the composition (the latter not analysed in this theme). The level of attention given by the child(ren) to the television screen, regardless of whether or not the television was included in the frame, was a key element of interest. The children photographed were absolutely focused on the television, to the exclusion of all else. Some images showed kids clearly distracted from another task-food or toys abandoned in favour of the screen-while others showed kids sitting on couches or the floor looking intensely up at the television. Where a group of children were pictured together, there was a comment exclaiming about how good it was that they were all watching the television together (presumably instead of getting into mischief). Like the "Pets" and "Snacks" motifs, the Instagram user's interest in television here is usually contextual rather than an expression of personal experience.

\section{Date Night}

Only a small number of images (six in total) fit into this theme, which was surprising - the colloquial use of "Netflix and chill" led the researcher to expect a greater number of images of couples watching television. These images certainly exist, but they did not appear in this dataset, possibly due to the lack of focus on actually watching television coded into \#netflixandchill. However, the six images were near identical in construction, presenting young heterosexual couple-selfies, all taken and posted by the woman in the photograph, and usually followed by a string of complimentary hashtags about the male in the picture: for example, "\#love \# of \#my \#life \#i \#love \#him", or "\#ilovehim \#himlovesme". It should be noted that many of the images of people with their animals used similar language, including \#soulmate. ${ }^{v}$ There were no images of non-hetero couples or groups in the dataset, although this does not preclude their existence within the hashtag despite not being represented in this data set. Indeed, there were images that referenced non-hetero sexualities, but these were selfies and point of view (feet up) shots; all were posted by one self-identifying gay man using other hashtags including \#gayguy, \#gayman, and \#gayboy.

\section{Daddy Time}

The final visual theme identified in the data set has been titled "daddy time". This shot featured a man, usually sitting on a couch either holding or beside a small child (baby, toddler, preschooler), with both subjects watching the television intently. The caption often referred to daddy's girl, or daddy's boy, as well as an exclamation about how lovely it was the child and parent were spending time together. The context of each shot and caption indicated that it was being taken by the child's other parent. The images were clearly taken without either party taking notice of the camera, and the angle usually suggested the photographer was standing at the edge of the room to snap the shot. The consistency of the composition and caption made this theme stand out, despite the fact that it was not common; as with the "Date Night" theme, only six of the images fit into the "Daddy Time" category. vi Here again sentiment and sentimentality are explicitly and intentionally performed, and watching television recedes to a context for that expression. Domesticity and domestic felicity "accumulate" here through multiple textual and visual cues, and the motif bares a strong resemblance to the casual, domestic, and personal photography of the private family photo album. 
These various motifs identified in the dataset represent patterns of persona work that are performed not through the consuming of television programs, but the contexts and conditions of watching. These contexts are consistently routine, banal, private or personal, and domestic as befitting a medium intimately tied to domestic spaces. The visual aesthetic of these images-often unpolished, informal, poorly lit, and amateur snapshots rather than compositions-affirms these conditions and seemingly makes invisible the persona work being done by the second screen that lies outside our field of vision - the implied but rarely articulated mobile phone/camera. It is an activity so readily implied that its labour is invisible. Indeed, the ubiquity of photography throughout so many aspects of contemporary life means that for many people, media production is a continual, banal process, made almost invisible by its prevalence. That people are sharing these amateur images publicly speaks to the intensity with which we produce our personas through digital imagery and networked visibility labour. This persona work is ongoing, largely invisible, can be laborious, while simultaneously being framed as a leisure activity for the bulk of users who do not receive income from their efforts.

The translation of the private space of the home into the public realm through the sharing of photographs demonstrates the comfort that many users have with the ubiquity of digital photography, as well as the role of sharing in curating and collaborating with micropublics. The use of Instagram also indicates the mediatised nature of the persona work. The identifiable visual themes in the photographs in this data set show that app-specific visual languages emerge from the user base, but are also enabled by the platform itself. The 1:1 ratio of most Instagram images persists despite the relaxation of the requirement from Instagram, while the point of view shot demonstrated in the "Feet Up" theme is facilitated by the always-to-hand nature of the smartphone camera. We can also see rejection of mediatised norms of behaviour in this dataset, with most images lacking the highly stylised, short depth of field, flat-lay "Instagram aesthetic" spruiked by many "how-to" blog posts.

These images garnered very few, if any, likes and comments, in a sense negating the collective nature of persona work. Although this visibility labour is an element of persona production, there are other elements of personas that do little to increase visibility and engagement. These images are, as noted earlier, a kind of personal communication and, despite their participation in a broad public hashtag, their intent or aim has more to do with the pleasures and gratifications of personal/self-expression, asserting oneself in public, and imagemaking and archiving than with asserting particular identities and leveraging their value and visibility amongst a broad community. To play with one's phone, to capture images, to frame them with hashtags that give meaningful context, and to post them on Instagram are activities that are labour, arguably pleasurable labour, but also iterative practices of persona production and performance in themselves regardless of the visual and textual content. And when such content is banal, amateur, and/or ambivalent about cultivating admiring or engaged publics, then the persona work of these practices warrants particular attention. Whether it is possible for researchers to engage with the full extent of this persona work is another question, however. The ephemerality of both emergent and established social media platforms and toolsSnapchat, for example, or Instagram and Facebook Stories, where posts are deleted after a set time-period-means that images and text, whether in the form of hashtags, captions, or annotations, are being produced and shared as transient, momentary artefacts. There remains resistance to the recording and maintaining of day-to-day banalities, making it difficult to gain a holistic understanding of these practices, or the platform vernaculars that are developing around them.

All of this points to the iterative, emergent nature of persona work, both in digitally networked spaces, and through our embodied selves. Practices and norms differ from space to 
space, platforms have their own vernacular languages (Gibbs et al. 2015), and their usage and popularity shift with time. As a result, our own practices as researchers must likewise remain responsive and reflexive. The five articles featured in this edition speak to a range of approaches to understanding persona in a variety of contexts, while our creative practice contribution visualises the relationships between different understandings of persona to draw connections between practice and theory.

\section{IN THIS ISSUE}

We begin this issue with a creative practice work. Aaron Humphrey takes on the familiar panel presentation of a comic, with hand-drawn illustration and imagery, to trace some important relationships between different types of studies of persona. Drawing on his work in User Experience Design (UXD), Humphrey examines the looping connections between UXD personas and social media profiles, questioning the wisdom of conflating the two while demonstrating how conceptually interrelated they are.

The first featured article, "I am in no way this': Troll hunters and pragmatic digital selfreference" (Michael Lee Humphrey) examines the contested persona of the online troll, as well as those who seek to expose the physical individual behind the digital representation. The dissonance between the online and embodied presentations asks questions of the perceived degree of distance between the two, and whether it is appropriate to hold one accountable for the actions of the other.

Following Humphrey's work are two articles that explore female fans and the objects of their attention and affection. Jocelyn Smith's piece "The politician/celebrity and fan(girl) pleasure: The line between Queen Hillary and Presidential Candidate Clinton" is a timely analysis of the construction (and then dismissal) of Clinton's female supporters as fangirls rather than politically engaged supporters. Smith investigates the relationship between the fangirl and Clinton's political persona and celebrity, and the impact these constructs had on Clinton's ability to seize the presidency and seize presidentiality.

In "Teenagers, fandom, and identity", Pilar Lacasa, Julián de la Fuente, María Ruth García-Pernía, and Sara Cortés examine how fans engage with popular celebrity personas through multimodal discourse. Reporting the results of ethnographic research into three different fan communities, the authors examine the varied ways that fans demonstrate their identification with, and contribute to the production of, the celebrities' personas.

Oskar Milik's "Persona in MMO games: Constructing an identity through complex player/character relationships" explores the complex relationships between players and their characters in online gaming. In the construct of the persona he finds a useful methodological paradigm for managing and making sense of the vast and unwieldy datasets that can emerge from studying the identity performances of both players and characters.

Finally, in this present cultural climate where truth or post-truth invokes and relies upon persona performances, Matteo Stocchetti proposes that parrhesia may have renewed significance in how we evaluate and understand social constructions of the real. Drawing on Foucault, "Persona and parrhesia: Research notes on the dialectics of the Real" investigates the conditions under which the authority of personas and the speech of personas are mutually legitimising, and the crucial role of risk and risky political speech that allows a persona to play the "parrhesiastic game", particularly in digital environments. 


\section{END NOTES}

i For example, it was impossible to determine from the image and caption whether the young woman who posted a selfie tagged with \#inspectorgadget was referring to the fact that she was watching the children's show, or the fact that she was wearing large, square-framed black glasses. Additionally, it is possible that some of the captions in languages other than English included references to shows that are not counted here. The diversity of captions, descriptions, and viewing choices complicates further textual analysis from this data. It is important to note that although all the posts in the dataset used \#watchingtv, this tag could have been incidental to the intended purpose of the photographer. In analysing the textual and visual components of the posts, we acknowledge that the findings are limited both to the dataset collected, and to the researcher's own interpretation of said dataset.

ii In terms of broadcast television, Fox, the Food Network, Golden Channel, and Discovery Channel were all named, as was ABC4Kids (an Australian-based children's channel). The streaming service Amazon Prime was named in one caption, as was $\mathrm{NC}+\mathrm{Go}$ (a Polish subscription-based streaming service).

iii Eighteen of the 340 images fell into this category, a surprisingly low figure-perhaps ones' food choices for television are simply too banal even now.

$\checkmark$ This adoption of affectionate language relates to the role of pets as companion animals, performing a surrogate role for either partners or children (Dotson \& Hyatt 2008; Sanders 1990; Veevers 1985).

vi What was also striking here was that the "daddy time" image was not mirrored by "mummy time". Rather, images of children with their mothers were taken as selfies. This contrasting display of the visualisation of parenting merits further study. In Doing family photography (2010), Gillian Rose noted that mothers take the bulk of family photos, saying that the mothers she spoke with reported having to make sure they were also represented in images and albums simply because they were more often behind the camera than in front of it. The role of mother as picture-taker would mean that mothers are simply less likely to be present in shared images unless they are simultaneously taking the picture. Also, it is possible these images reflect a socio-cultural expectation that sees any time that a father spends with their child as noteworthy, and therefore worth recording. This relates to the idea of dads "babysitting" their own children (Coe 2013; Garcia 2016; Toalson 2016), while mothers caring for children is so normalised as to be invisible and therefore unworthy of photography. Although divisions of labour within the home, and around childcare in particular, have been changing, the role of the father as caregiver is still finding its feet, which may also contribute to their representation in these images.

\section{WORKS CITED}

Abidin, C 2016a, “Aren't these just young, rich women doing vain things online?': Influencer selfies as subversive frivolity', Social Media + Society, vol. 2, no. 2. DOI: $10.1177 / 2056305116641342$

Abidin, C 2016b, 'Visibility labour: Engaging with Influencers' fashion brands and \#OOTD advertorial campaigns on Instagram', Media International Australia, vol. 161, no. 1, pp. 86-100. 
Alam, MH, Ryu, WJ \& Lee, SK 2017, 'Hashtag-based topic evolution in social media', World Wide Web: Internet and Web Information Systems, vol. 20, no. 6, pp. 1527-1549.

Appleton, N 2017, 'The reason I don't share photos of my child online, and don't think you should either', Mamamia, 23 April, retrieved 30 November 2017, <http://www.mamamia.com.au/sharing-photos-of-your-kids-online/>.

Barbour, K 2016, 'Public audiencing: Using Twitter to study audience engagement with characters and actors', in M Griffiths \& K Barbour (eds), Making publics, making places, University of Adelaide Press, Adelaide.

Barthes, R 1981, Camera Lucida, Vintage, London.

Baym, NK 2000, Tune in, log on: Soaps, fandom, and online community, SAGE, Thousand Oaks.

Blatchford, E 2017, 'Should you post photos of your child on social media?', Huffington Post, 30 August, retrieved 30 November 2017, <http://www.huffingtonpost.com.au/2017/08/29/should-you-post-photos-of-yourchild-on-social-media a $23190070 />$.

Brown, Z \& Tiggemann, M 2016, 'Attractive celebrity and peer images on Instagram: Effect on women's mood and body image', Body Image, vol. 19, pp. 37-43.

Coe, A 2013, 'Dads caring for their kids: It's parenting, not babysitting', The Atlantic, 23 January, retrieved 30 November 2017, <https://www.theatlantic.com/sexes/archive/2013/01/dads-caring-for-their-kids-itsparenting-not-babysitting/267443/>.

Dejmanee, T 2016, “Food porn' as postfeminist play: Digital femininity and the female body on food blogs', Television \& New Media, vol. 17, no. 5, pp. 429-448.

Djafarova, E \& Rushworth, C 2017, 'Exploring the credibility of online celebrities' Instagram profiles in influencing the purchase decisions of young female users', Computers in Human Behavior, vol. 68, pp. 1-7.

Dotson, MJ \& Hyatt, EM 2008, 'Understanding dog-human companionship', Journal of Business Research, vol. 61, no. 5, pp. 457-466.

Duguay, S 2016, 'Lesbian, gay, bisexual, trans, and queer visibility through selfies: Comparing platform mediators across Ruby Rose's Instagram and Vine presence', Social Media + Society vol. 2, no. 2. DOI: $10.1177 / 2056305116641975$

Garcia, J 2016, 'No, fathers aren't babysitters, they're parents', The Good Men Project, 17 August, retrieved 30 November 2017, <https://goodmenproject.com/featured-content/nofathers-arent-babysitters-theyre-parents-dg/>.

Gibbs, M, Meese, J, Arnold, M, Nansen, B \& Carter, M 2015, '\#Funeral and Instagram: death, social media, and platform vernacular', Information, Communication \& Society, vol. 18, no. 3, pp. 255-268. DOI: 10.1080/1369118X.2014.987152

Haelle, T 2016, 'Do parents invade children's privacy when they post photos online?', NPR, 28 October, retrieved 30 November 2017, <https://www.npr.org/sections/healthshots/2016/10/28/499595298/do-parents-invade-childrens-privacy-when-they-postphotos-online>.

Hand, M 2012, Ubiquitous photography, Polity, Cambridge.

Highfield, T \& Leaver, T 2015, 'A methodology for mapping Instagram hashtags', First Monday, vol. 20, no 1, https://firstmonday.org/ojs/index.php/fm/article/view/5563.

Highfield, T \& Leaver, T 2016, 'Instagrammatics and digital methods: studying visual social media, from selfies and GIFs to memes and emoji', Communication Research and Practice, vol. 2, no. 1, pp. 47-62. DOI: 10.1080/22041451.2016.1155332.

Kelion, L 2017, 'Posting children's photos divides nation', BBC News, 3 August, retrieved 30 November 2017, <http://www.bbc.com/news/technology-40804041>.

Leaver, T \& Highfield, T 2018, 'Visualising the ends of identity: pre-birth and post-death on Instagram', Information, Communication \& Society, vol. 21, no. 1, pp. 30-45. DOI: 10.1080/1369118X.2016.1259343.

Lee, K 2016, 'Making cents of contemporary intimacies: the private in the public', in PD Marshall, G D'Cruz, S McDonald \& K Lee (eds), Contemporary publics, Palgrave Macmillan, London, pp. 217-228. 
Manovich, L 2016, Instagram and contemporary image, Cultural Analytics Lab, retreived 24 January 2017, <http://manovich.net/index.php/projects/instagram-andcontemporary-image $>$.

Markham, L 2015, 'The Meringue War', Virginia Quarterly Review, vol. 91, no. 2, pp. 56-61.

Marshall, PD 2014, 'Persona Studies: mapping the proliferation of the public self', Journalism, vol. 15 , no. 2 , pp. 153-170.

Moon, JH, Lee, E, Lee, J-A, Choi, TR \& Sung, Y 2016, 'The role of narcissism in self-promotion on Instagram', Personality and Individual Differences, vol. 101, pp. 22-25.

Moore, C, Barbour, K \& Lee, K 2017, 'Five dimensions of online persona', Persona Studies, vol. 3, no. 1, pp. 1-12.

Moreno, MA, Ton, A, Selkie, E \& Evans, Y 2016, 'Secret society 123: Understanding the language of self-harm on Instagram', Journal of Adolescent Health, vol. 58, no. 1, pp. 78-84.

Olszanowski, M 2014, 'Feminist self-imaging and Instagram: Tactics of circumventing Sensorship', Visual Communication Quarterly, vol. 21, no. 2, pp. 83-95.

Orlando, J 2016, 'Think again before you post online those pics of your kids', The Conversation, 27 December, retrieved 30 November 2017, <http://theconversation.com/think-againbefore-you-post-online-those-pics-of-your-kids-70579>.

Pittman, M \& Reich, B 2016, 'Social media and loneliness: Why an Instagram picture may be worth more than a thousand Twitter words', Computers in Human Behavior, vol. 62, pp. 155-167.

Radesky, J \& Christakis, D 2016, 'Media and young minds', Pediatrics, vol. 138, no. 5.

Rose, G 2010, Doing family photography: the domestic, the Public and the politics of sentiment, rematerialising cultural geography, Ashgate Publishing Ltd, Farnham.

Sanders, CR 1990, 'The animal "Other": Self definition, social identity and companion animals', NA - Advances in Consumer Research, vol. 17, pp. 662-668.

Slater, D 1995, 'Domestic photography and digital culture', in M Lister (ed.), The photographic image in digital culture, Routledge, London, pp. 129-146.

Sontag, S 1979, On photography, Penguin, Harmondsworth.

Toalson, R 2016, 'A dad is not a babysitter or a helper. He's a parent', Huffington Post, 6 December, retrieved 30 November 2017, <https://www.huffingtonpost.com/racheltoalson/a-dad-is-not-a-babysitter-or-a-helper b 8911878.html>.

Veevers, JE 1985, 'The social meaning of pets', Marriage \& Family Review, vol. 8, no. 3-4, pp. 1130.

Zappavigna, M 2016, 'Social media photography: construing subjectivity in Instagram images', Visual Communication, vol. 15, no. 3, pp. 271-292. 